\title{
Impulsive Corona Discharges for Fine Particles Precipitation in a Coaxial Topology
}

\author{
A. C. Mermigkas, Student Member, IEEE, I. V. Timoshkin, Member, IEEE, S. J. MacGregor, \\ Member, IEEE, M. J. Given, Senior Member, IEEE, M. P. Wilson, Member, IEEE, and T. Wang
}

\begin{abstract}
Air-borne micrometer and sub-micrometer particles produced by anthropogenic sources contaminate atmospheric air, especially in large cities where both population and industrial activities are higher leading to a reduced air quality. Recent research has pointed out particles less than $2.5 \mu \mathrm{m}$ in diameter (PM2.5) as a potential health hazard. To address this issue stricter legislation has been put into force in order to reduce PM2.5 emissions. This paper is focused on the development of an impulsive micro-electrostatic precipitation technology for charging and removal of fine air-borne particles in an economically feasible way. In the present work a compact, coaxial precipitator has been developed for possible indoor air cleaning applications. HV impulses together with de voltage has been used for energisation of the reactor as it has been shown to enhance the precipitation efficiency. This precipitation system has been used for removal of fumes and fine airborne particles from ambient air. In addition to the experimental part, analytical work has been conducted in order to optimize the electrostatic precipitation process and to reduce its power consumption.
\end{abstract}

Index Terms-Air pollution, electrostatic precipitation, impulsive corona, particle charging, plasma applications, PM2.5.

\section{INTRODUCTION}

$\mathrm{I}_{\mathrm{i}}^{\mathrm{v}}$ MPULSIVE corona discharges in atmospheric air are used in practical environmental applications including surface cleaning and biological decontamination [1], [2], decomposition of chemical pollutants (e.g., $\mathrm{NO}_{\mathrm{x}}$ and others), [3], [4], and precipitation of fine and ultra-fine air-borne particulate matter, [5]-[7]. Such discharges are generated through energisation of electrodes within a treatment reactor with high-voltage impulses, resulting in the development of transient non-thermal plasmas. The reactive species produced by the plasma induce electric charge on air-borne solid particles; in addition, they can effectively inactivate microorganisms and decompose harmful chemical species. The physical and chemical characteristics of transient corona

Manuscript received December 17, 2013. This work was supported in part by EPSRC, under Grant EP/H049428/1 "Impulsive Micro-Electrostatic Precipitation Systems" awarded in 2010 and EPSRC Pathway to Impact Grant Awarded in 2012. The work of A. C. Mermigkas was supported by the Faculty of Engineering and the Department of Electronic and Electrical Engineering, University of Strathclyde.

The authors are with the Department of Electronic and Electrical Engineering, University of Strathclyde, Glasgow G1 1XW, U.K. (e-mail: athanasios.mermigkas@strath.ac.uk; igor.timoshkin@strath.ac.uk; scott. macgregor@strath.ac.uk; m.given@strath.ac.uk; mark.p.wilson@strath.ac.uk; tao.wang@strath.ac.uk). plasma discharges in air have been extensively studied e.g., [8], [9], and the results of these studies form a basis for the development and optimisation of technological applications of such plasmas. The present paper is focused on an investigation of the use of impulsive corona discharges in atmospheric air for charging and removal of fine and ultra-fine particulate matter from an air flow. This work continues the study of the impulsive micro-electrostatic precipitation process initiated by the authors; previously obtained results on impulsive precipitation of powder particles and charging mechanisms in the transient corona discharges are published in [6], [10].

PM2.5 particles have been identified as a potential health hazard and new legislative acts which require reduction in emission of PM2.5 particles have come into force, [11], [12]. Therefore, new methods are required in order to control the concentration of air-borne fine and ultra-fine particles. In the present paper, the performance of a two-stage precipitation reactor is reported. This was developed to improve the efficiency of the micro-electrostatic precipitation process, while keeping energy consumption at a low level. The first stage of the reactor, the charging stage, employs $\mu$ s impulses. The second stage uses a dc voltage for the precipitation of the charged particles. The short HV impulses in the first stage of the reactor generate an enhanced electric field without complete spark breakdown, thus the saturation charge that the air-borne particles accumulate in the reactor can be increased and precipitation efficiency will be enhanced [13]. Additionally, it is expected that these short HV impulses will reduce energy consumption as compared with continuous energisation, [14]. The dc voltage applied to the second stage of the precipitator was kept below corona ignition level to reduce overall power consumption. It has been shown that a two-stage precipitation reactor requires a lower energisation voltage compared to a single-stage reactor, [13]. This, in combination with positive-polarity energisation, helps to reduce the concentrations of ozone and nitrogen oxides produced during operation of the precipitator, [13], [15], [16]. Ozone concentration was measured during operation of the reactor and the results are reported in Section III(B).

An important parameter which determines the level of precipitation efficiency is the terminal migration velocity that the air-borne particles achieve. This terminal velocity depends on the charging rate of particles, which in turn depends on the permittivity and conductivity of the particle and the external medium, as well as the particle dimensions and particle loading of the air flow. In the present paper, a numerical analysis has been attempted for evaluation of the particle 
migration velocity inside the reactor. In the experimental part of the paper, the precipitation efficiency of airborne particles has been investigated using different energisation regimes and different combinations of particle-laden gases (test fluids), including ambient laboratory air and air with various concentrations of beeswax candle fumes. Experimental particle velocities have been obtained using the MattsÖhnfeldt empirical equation [17] and compared with analytical values.

\section{EXPERIMENTAL ARRANGEMENT}

\section{A. Experimental System}

The precipitation reactor used in the present study is similar to the two stage system developed in [6], however it is larger in scale. Both stages have a cylindrical, coaxial topology. The first stage, intended for particle charging, has a thin $(0.213$ $\mathrm{mm}$ diameter) wire which is stressed with HV impulses of $\mu \mathrm{s}$ duration. The outer electrode is an earthed stainless steel tube with an inner diameter of $95 \mathrm{~mm}$ and a length of $87 \mathrm{~cm}$. The second stage is intended for particle deflection and their removal from the airflow, this has a coaxially-located smooth rod of $5 \mathrm{~mm}$ diameter which is stressed with dc HV. The outer electrode is an earthed stainless steel tube of $88 \mathrm{~mm}$ internal diameter and $74 \mathrm{~cm}$ length.

The HV impulses applied to the wire electrode of the first stage of the reactor are produced by an impulse generator, based on a step-up autotransformer. In the second stage of the reactor, the central $\mathrm{HV}$ electrode is energized with dc voltage by a $20 \mathrm{kV}$ Glassman EW series HV dc power supply. A Tektronix P6015A HV probe (75 MHz bandwidth) was used to measure the impulsive voltage across the reactor, while a $1 \mathrm{k} \Omega$ current viewing resistor was used to measure the current. A schematic diagram of the precipitation system used in the present study is given in Fig.1, and a detailed description of the generator and electrical diagnostic system can be found in [6].

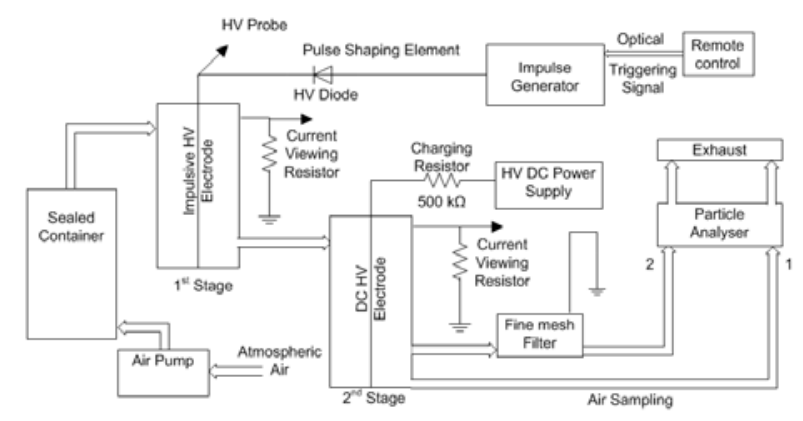

Fig. 1. Schematic diagram of the precipitation system.

The voltage and current waveforms across the reactor are shown in Fig. 2. The amplitude of the HV impulses was +30 $\mathrm{kV}$, the full width at half maximum impulse duration was 500 $\mu \mathrm{s}$, and no voltage reversal was observed. When the first stage of the reactor is stressed with an HV impulse of such magnitude, a current impulse in this stage of the reactor is observed, which was measured at $\sim 10 \mathrm{~mA}$ (peak value). This current impulse represents a transient corona discharge which is responsible for particle charging. The displacement current due to the capacitance of the reactor is much smaller than this current impulse, and as a result, the charge associated with the displacement current $(\sim 220 \mathrm{nC})$ is much lower than the $\sim 1 \mu \mathrm{C}$ per pulse released by the corona plasma discharge.

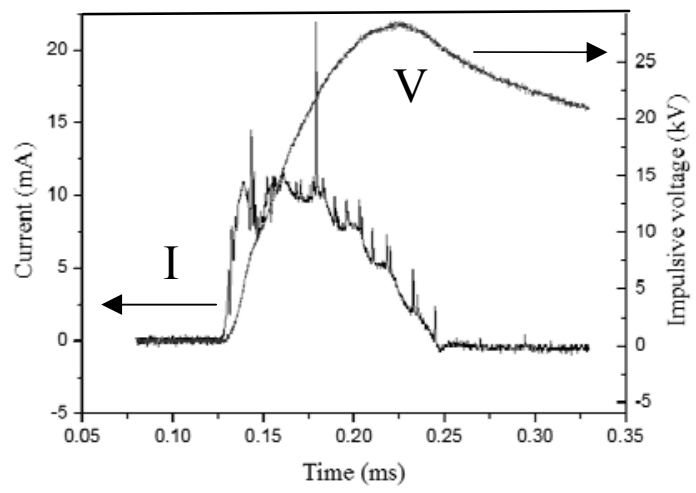

Fig. 2. Voltage (V) and current (I) waveforms of individual impulses.

The air-pump is used to provide an air flow inside the reactor with the flow rate of $16 \ell / \mathrm{min}$ for atmospheric air tests or $3 \mathrm{l} / \mathrm{min}$ for beeswax candles tests.

\section{B. Particle Selection and Detection}

Precipitation tests commenced with the particles that were already present in ambient laboratory air. Then, precipitation tests were conducted using beeswax candle fumes, which consists mainly of particles in the PM2.5 range. In all tests a portable laser aerosol spectrometer 1.109 (Grimm Aerosol $\mathrm{GmbH}$ ), was used to measure the number of particles, allowing the precipitation efficiency to be calculated. This spectrometer is able to measure the number of particles per liter in 31 size ranges (from $250 \mathrm{~nm}$ to $>32 \mu \mathrm{m}$ ) in real time. Depending on the concentration of particles in the air flow, the particle analyser was connected either directly to the output of the second stage of the precipitation reactor (path 1, Fig.1), or via a stainless-steel earthed woven mesh filter made out of $28 \mu \mathrm{m}$ diameter stainless steel threads. This filter, used to improve the efficiency of the precipitator, has an aperture 99 $\mu \mathrm{m}$, significantly larger than the size of particles (path 2 , Fig.1).

\section{EXPERIMENTAL RESULTS}

\section{A. Ambient Air}

A sealed container of $\sim 14 \ell$ volume is supplied by an air pump which produces an air flow with a flow-rate of $16 \ell / \mathrm{min}$. This container was connected through four $6 \mathrm{~mm}$ diameter plastic tubes to the first stage of the precipitation reactor. The particle analyser was sampling air directly from the exhaust of the second stage, (path 1, Fig.1).

In all precipitation tests (conducted at ambient temperature, pressure and humidity) the following procedure was used. 
Firstly, the particle analyser was turned on for $30 \mathrm{~s}$ without any air flow. Then the air pump was turned on for 4 min and $30 \mathrm{~s}$ in order to produce constant concentration of background particles delivered into the micro-electrostatic precipitation $(\mu$ ESP) reactor. As soon as the concentration of background particles stabilized the precipitation reactor was energized for $5 \mathrm{~min}$. After the tests, the air pump was left on for $\sim 15 \mathrm{~min}$ in order to re-introduce the nominal levels of air-borne particles for the next experiment.

The precipitation efficiency, $\eta_{p}$, for each range of particle sizes was calculated as $\left(N_{\max }-N(t)\right) / N_{\max }$, where $N(t)$ is a number of particles at time intervals of $10 \mathrm{~s} ; N_{\max }$, is the maximum number of particles prior the energisation of the reactor. Then the arithmetic average of these values was calculated representing the efficiency for each test. The average and the standard deviation for the tests with the same energisation were calculated. The results (pass rate, $\left(1-\eta_{p}\right) \cdot 100 \%$, as a function of particle size) are given in Fig.3.

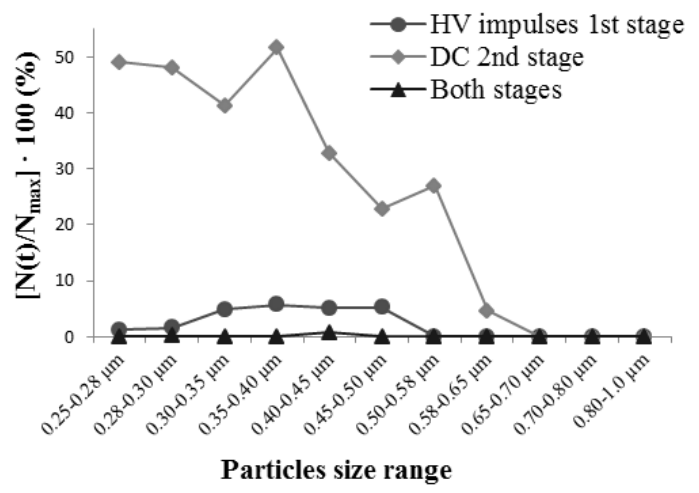

Fig. 3. Pass rate for different size ranges and different energisation modes for ambient air tests. First stage was energized with $\mathrm{HV}$ impulses of $+30 \mathrm{kV}$ at $50 \mathrm{pps}$. Second stage was stressed with $+17 \mathrm{kV}$ dc.

It can be seen that precipitation takes place even without impulsive energisation of the first, charging stage of the precipitator, when only the second dc stage is being energised with voltages below the corona ignition voltage. This is due to the particles acquiring charge by friction in the fluid delivery system. Energisation of the first, impulsive stage only increases the precipitation efficiency, and if both stages are energised, the precipitation efficiency is $\sim 100 \%$.

\section{B. Beeswax Candle Fumes}

Heavy particle loading can have a detrimental effect on the smooth operation of an electrostatic precipitator. Precipitation efficiency with significantly higher particle loading was investigated using fumes produced by beeswax candles. It has been found that precipitation efficiencies are lower in almost all cases as compared with the ambient air test (when the same energisation regimes are used), reaching $\sim 99 \%$ for the combined energisation.

A different approach to efficiency calculation has been taken in the case of tests with beeswax fumes. Instead of having to wait for specific time intervals as in the atmospheric air tests, data gathering started from the beginning of the test and lasted until the candles burnt out or they were extinguished. The average number of particles was calculated $50 \mathrm{sec}$ after the maximum number of particles of the $250-280$ nm range, $N_{\max }$, was detected.

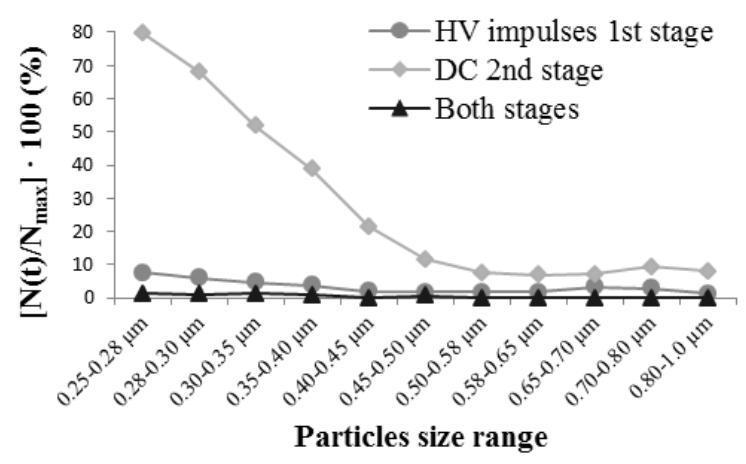

Fig. 4. Pass rate for all possible energisation modes. First stage was energized with $\mathrm{HV}$ impulses of $+30 \mathrm{kV}$ at $50 \mathrm{pps}$. Second stage was stressed with $+17 \mathrm{kV}$ dc. Particles were produced by a single beeswax candle.

Fig. 4 gives the precipitation results (pass rates) of the tests with fumes produced by a single candle for different energisation regimes. This figure shows that the most efficient precipitation has been obtained in the case when both stages of the reactor, impulsive and dc, are energized. Similar results were obtained by the authors with the smaller scale reactor and cigarette smoke as a test fluid, [6]. Figs. 5-6 present precipitation results (pass rates) for heavier particle loading. To these ends two and three candles were burned inside the container and its fumes were fed into the precipitation reactor.

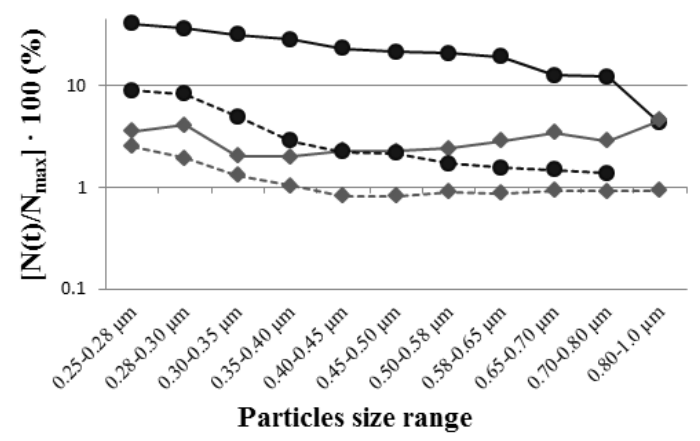

Fig. 5. Pass rate for the first stage (circles) and for both stages (diamonds) energised. Solid lines, no mesh filter; dashed lines, mesh filter is included. First stage, HV impulses +30 kV, 50 pps. Second stage; +17 kV dc. Particles were produced by two beeswax candles.

It can be seen that the efficiency is lower compared to the single candle test and in the case of the smallest detectable size range $(250-280 \mathrm{~nm})$ the decrease in efficiency is more than $\sim 30 \%$. However, if the fine mesh filter is inserted between the precipitator output and the particle detector, the precipitation efficiency improves substantially. In the case of combined energisation, the precipitation efficiency is only 
$\sim 1 \%-1.5 \%$ lower compared to the test with a single candle, depending on the size range.

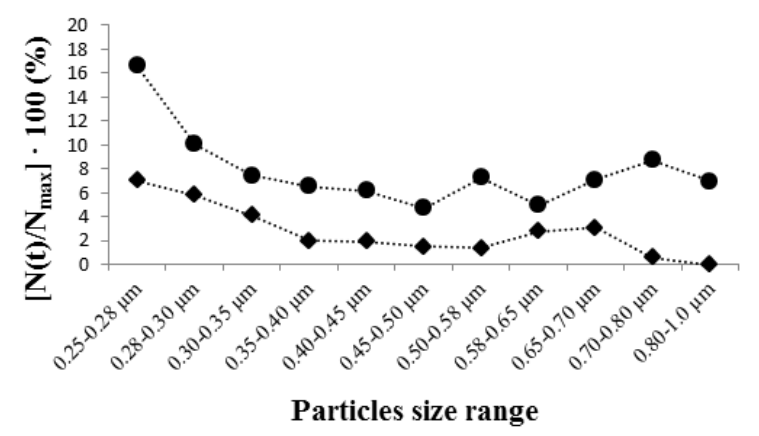

Fig. 6. Pass rate for the first stage (circles) and for both stages (diamonds) energised. Fine mesh filter was always used. First stage was energized with $\mathrm{HV}$ impulses of $+30 \mathrm{kV}$ at 100 pps. Second stage was stressed with $+17 \mathrm{kV}$ dc. Particles were produced by three beeswax candles.

If 3 candles were used, the fine mesh wire filter was always used to avoid overloading of the particle analyser. In addition to that, it was decided to double the pulse repetition rate in the first stage in order to enhance the particulate charging process. It has been shown that the efficiency is still higher when both stages are energised compared to when only the first stage is energised. Similar tendencies with efficiency dropping due to heavy loading of soot particles were reported in [7].

Another important factor which should be taken into account in the design of electrostatic precipitation systems for practical applications is the potential for secondary contamination of the air with ozone. In the present reactor, ozone production is minimized by the use of positive HV impulses in the charging stage, and by stressing the precipitation stage with a voltage below the corona ignition threshold. This results in an ozone concentration of $0.17 \mathrm{ppm}$ at the outlet of the precipitation system, as measured by an Ecosensor A-21ZX ozone detector. The use of a manganese dioxide filter reduces the ozone concentration in the outlet air flow down to the background level, 0.01-0.02 ppm.

\section{Analysis of the Particle Motion Inside the MICRO-ESP REACTOR}

There are several factors that define the efficiency of electrostatic precipitation, and one of the most important is the terminal migration velocity of the particles in the precipitation reactor. To obtain the dynamic characteristics of particles, the equation of motion inside the vertically located cylindrical corona reactor must be solved. The forces exerted on a test particle on the radial, r-direction are given in (1), where $F_{\text {drag }}$ is the drag force that acts opposite of the direction of motion of the particle, $F_{e}$ is the Coulomb force that acts on the particle due to its charge and $F_{T o t}$ is the sum of the forces exerted upon the particle. The weight can be disregarded in the case of vertical deployment of the precipitator as the migration velocity component will be radial.
In the above equation, $Q$ is the total conduction charge acquired by the particle, $\eta$ is the viscosity of air, $C_{c}$ is the Cunningham correction factor, [18], and $d$ is the particle diameter. In order to calculate the electric field, various parameters must be obtained, see [6]. One required parameter is the ionisation radius around the wire which is the boundary of the ionisation and the ion transport zones of the corona discharge.

The critical ionisation field in atmospheric air, $E_{\text {crit }}$, tends to its saturation value of $(26-31) \cdot 10^{5} \mathrm{~V} / \mathrm{m}$; it is suggested that this field corresponds to equal ionisation and attachment coefficients in air. In order to identify the radius of the ionization zone, Kapzov's hypothesis can be used. According to this hypothesis, the electric field at the corona electrode remains constant for voltages above the corona ignition voltage. This expression has been derived using the assumption that the mobility of the charge carriers, $\mu$, is constant, therefore $\mu$ can be obtained by fitting an analytical voltage-current $(V-I)$ curve, to the experimental $V-I$ data found in [6]. Therefore, the equation of motion of the particle is:

where $C_{0-3}$ are constants. $C_{0} \cdot, C_{l}$, and $C_{2} / r^{2}$ have dimensions of force, constants $C_{0}, C_{1}$ and $C_{2}$ contain information on particle permittivities, conductivities, size, viscosity of fluids and other parameters; $C_{3}$ is the MaxwellWagner relaxation time. The full analytical expressions of these constants can be found in [6].

This equation has been solved numerically using Matlab software (ode45 solver). The particle migration velocity during high voltage impulse as a function of time for $250 \mathrm{~nm}$ particles with a relative permittivity of $\varepsilon_{p}=2.4$ and conductivities in the range of $\mu \mathrm{S}$ (which are characteristics for beeswax particle, [19], [20]) are shown in Fig.8.

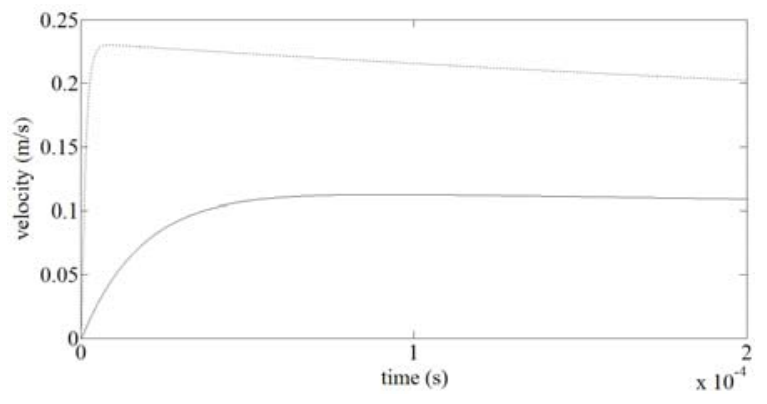

Fig. 8. Particle migration velocity as a function of time for a $250 \mathrm{~nm}$ particle, $\varepsilon_{p}=2.4$ solid line $\sigma_{\mathrm{p}}=10^{-6} \mathrm{~S} / \mathrm{m}, \sigma_{\mathrm{m}}=5.76 \cdot 10^{-7} \mathrm{~S} / \mathrm{m}$; dotted line $\sigma_{\mathrm{p}}$ $=1.25 \cdot 10^{-5} \mathrm{~S} / \mathrm{m}, \sigma_{\mathrm{m}}=10^{-5} \mathrm{~S} / \mathrm{m}$.

Fig. 8 shows that the particles achieve their maximum migration velocities during $\leq 100 \mu$ s of the applied impulse, which was the current pulse duration used for charging of 
particles in the first precipitation stage. This duration of $\mathrm{HV}$ impulse ensures that particles acquire maximum velocity which is important factor for precipitation efficiency. Preliminary analysis of the radial dependence of the particle migration velocity has also been conducted. In order to calculate the terminal velocity of particles it was assumed that the first stage was energized with sufficiently long impulses which allow a particle to reach the collection electrode while the field was still acting on this particle. It has been shown that the terminal velocity for a particle located $0.5 \mathrm{~mm}$ away from the HV electrode is only $\sim 22 \%$ greater compared with the terminal velocity acquired by a particle located $0.5 \mathrm{~mm}$ away from the collection electrode. It has also been shown that once the particles have left the high field region close to the inner conductor that there is little variation in their terminal velocity. This data will help optimise the design of precipitators by maximising the probability that particles will impact the collection electrode before they have travelled the full length of the precipitator.

The precipitation efficiency can be obtained by the MattsÖhnfeldt empirical equation, [17]:

$\eta=1-e^{-\left(\frac{A \cdot u_{d}}{Q}\right)^{\kappa}}$

where $\eta$ is the collection efficiency, $A$ is the collection area, $u_{d}$ is the effective migration velocity, $Q$ is the gas flow rate, and $\kappa$ is a constant from 0.4-0.6, [21]. Using the calculated terminal velocities for long impulses, the precipitation efficiency obtained by (3) is $\sim 100 \%$ for particles with practically all dimensions considered in the present study However, precipitation efficiencies, $\eta_{p}$, obtained in the tests in which $100 \mu$ s energisation pulses were used, are below $100 \%$ for some particle sizes as discussed in Section III. The calculated terminal velocities obtained by (3) using experimental values of $\eta_{p}$, are given in Table 1 .

TABLE I

Drift velocity extracted from experimental data $(\mathrm{mm} / \mathrm{s})$

\begin{tabular}{|cccc|}
\hline Particle diameter & ambient air & 1 candle & 2 candles \\
\hline \hline $0.25-0.28 \mu \mathrm{m}$ & $\mathbf{8 . 0 3}$ & $\mathbf{2 . 0 5}$ & $\mathbf{0 . 1 5}$ \\
$0.45-0.50 \mu \mathrm{m}$ & $\mathbf{2 . 9 1}$ & $\mathbf{6 . 3 2}$ & $\mathbf{0 . 5 8}$ \\
$0.70-0.80 \mu \mathrm{m}$ & $*$ & 4.54 & 1.27 \\
\hline
\end{tabular}

* Denotes that $\eta$ was $100 \%$ thus no terminal velocity could be calculated.

This analysis shows that potentially the precipitation efficiency can be improved by increasing the terminal velocity of particles in the precipitator. This potentially can be achieved using an increased pulse repetition rate. Several other factors should also be considered in the analysis of the precipitation efficiency using the empirical equation (3): according to [21], (3) gives lower efficiencies compared to experimental data; heavy particle loading also can significantly reduce the precipitation efficiency, [22].

\section{SUMmary}

The precipitation efficiency for dc, impulsive, and combined dc and impulsive energisation, in a two-stage, cylindrical precipitator has been investigated. It was shown that the efficiency of the removal of particles from ambient air can reach $\sim 100 \%$, while precipitation efficiency in the tests with beeswax candle fumes was $\sim 99-100 \%$ depending on the particle size range. These results are in line with the data previously obtained for cigarette smoke in a smaller scale, double-stage micro-ESP reactor [6]. In order to minimise the energy consumption, the second stage of the precipitator was energized with $\mathrm{DC}$ voltages below the corona ignition level which resulted in $\sim 60 \%$ power reduction (down to $\sim 1 \mathrm{~W}$ ) as compared with the reactor described in [6] at the same precipitation efficiency. The analytical analysis of particle velocities conducted in this work demonstrated that particles achieve their maximum velocities during $\sim 100 \mu$ s. This analysis allowed selection of the optimal energisation high voltage pulse width to be made. It was also shown that the migration velocity increases with an increase in dielectric permittivity of air-borne particles. The obtained results prove that the combination of impulsive and dc energisation in the two stage precipitation systems with addition of a fine mesh filter can effectively remove different types of air-borne fine particles from air flow. Systems with higher flow-rate than those used in the present study may find practical application for indoor air-cleaning processes. Potentially this technology could help in combating the PM constituent of air pollution in indoor spaces, and thus passively improving people's health.

\section{REFERENCES}

[1] I. V. Timoshkin, M. Maclean, M. P. Wilson, M. J. Given, S. J. MacGregor, W. Tao, and J. G. Anderson, "Bactericidal Effect of Corona Discharges in Atmospheric Air," IEEE Trans. on Plasma Science, vol. 40, no. 10, pp. 2322-2333, 2012.

[2] S. Li, I. V. Timoshkin, M. Maclean, S. J. MacGregor, M. P. Wilson, M. J. Given, J. G. Anderson, and W. Tao, "Steady-State Corona Discharges in Atmospheric Air for Cleaning and Decontamination," IEEE Trans. on Plasma Science, vol. 41, no. 10, pp. 2871-2878, 2013.

[3] E. H. W. M. Smulders, B. E. J. M. Van Heesch, and S. S. V. B. van Paasen, "Pulsed power corona discharges for air pollution control," IEEE Trans. on Plasma Science, vol. 26, no. 5, pp. 1476-1484, 1998.

[4] Y. Yankelevich, and A. Pokryvailo, "High-power short-pulsed corona: investigation of electrical performance, $\mathrm{SO}_{2}$ removal, and ozone generation," IEEE Trans. on Plasma Science, vol. 30, no. 5, pp. 19751981, 2002.

[5] A. Mizuno, "Electrostatic precipitation," IEEE Trans. on Dielectrics and Electrical Insulation, vol. 7, no. 5, pp. 615-624, 2000.

[6] A. C. Mermigkas, I. V. Timoshkin, S. J. MacGregor, M. J. Given, M. P. Wilson, and T. Wang, "Removal of Fine and Ultrafine Particles From Air by Microelectrostatic Precipitation," IEEE Trans. on Plasma Science, vol. 41, no. 10, pp. 2842-2850, 2013.

[7] F. J. C. M. Beckers, W. F. L. M. Hoeben, T. Huiskamp, A. J. M. Pemen, and E. J. M. van Heesch, "Pulsed Corona Demonstrator for SemiIndustrial Scale Air Purification," IEEE Trans. on Plasma Science, vol. 41, no. 10, pp. 2920-2925, 2013.

[8] P. P. M. Blom, "High-Power Pulsed Corona," PhD Thesis, Technische Universiteit Eindhoven, Eindhoven, 1997.

[9] H.-H. Kim, "Nonthermal Plasma Processing for Air-Pollution Control: A Historical Review, Current Issues, and Future Prospects," Plasma Processes and Polymers, vol. 1, no. 2, pp. 91-110, 2004.

[10] A. C. Mermigkas, I. V. Timoshkin, S. J. MacGregor, M. J. Given, M. P. Wilson, and T. Wang, "Superposition of DC Voltage and 
Submicrosecond Impulses for Energization of Electrostatic Precipitators," IEEE Trans. on Plasma Science, vol. 40, no. 10, pp. 2388 $-2394,2012$

[11] Directive 2008/50/EC of the European parliament and of the council of 21 May 2008 on ambient air quality and cleaner air for Europe, Official J. Eur. Union, vol. L 152, pp 1-44, Jun. 11, 2008. [Online]. Available: http://rod.eionet.europa.eu/instruments/633.

[12] USEPA. "History of the National Ambient Air Quality Standards for Particulate Matter During the Period 1971-2012," Jun. 11, 2013 [Online]. http://www.epa.gov/ttn/naaqs/standards/pm/s pm history.html.

[13] H. J. White, Industrial Electrostatic Precipitation: Addison-Wesley Publishing company, INC., 1963.

[14] G. Dinelli, V. Bogani, and M. Rea, "Enhanced Precipitation Efficiency of Electrostatic Precipitators by Means of Impulse Energization," IEEE Trans. on Industry Applications, vol. 27, no. 2, pp. 323-330, March/April 1991.

[15] M. B. Awad, and G. S. P. Castle, "Ozone Generation in an Electrostatic Precipitator With a Heated Corona Wire," Journal of the Air Pollution Control Association, vol. 25, no. 4, pp. 369-374, 1975/04/01, 1975.

[16] C. Asbach, T. A. J. Kuhlbusch, and H. Fissan, "Effect of corona discharge on the gas composition of the sample flow in a Gas Particle Partitioner," Journal of Environmental Monitoring, vol. 7, no. 9, pp. 877-882, 2005.

[17] S. Matts, and P. O. Öhnfeldt, "Efficient gas cleaning with SF electrostatic precipitators," AB Svenska Fläktfabriken Review, vol. 6-7, pp. 91-110, 1964.

[18] W. C. Hinds, Aerosol Technology, Properties, Behaviour and Measurement of Airborne Particles, 1st ed. New York, Wiley, 1982.

[19] H. W. Sams, and Co, Handbook of electronic tables \& formulas, 4th ed.: Sams, 1973, pp. 51

[20] M. Nyayate, and J. Pendharkar, "Measurement of Dielectric constant of unprocessed Indian Bee Wax, using IC 555 timer and measurement of change in its resistivity with Temperature," Golden research thoughts, vol. 1, no. XII, pp. 1-4, 2012.

[21] G.-Y. Lin, T.-M. Chen, and C.-J. Tsai, "A Modified Deutsch-Anderson Equation for Predicting the Nanoparticle Collection Efficiency of Electrostatic Precipitators," Aerosol and Air Quality Research, vol. 12, no. 5, pp. 697-706, 2012.

[22] J. S. Chang, P. C. Looy, and C. Webster, "The effects of dust loadings on the collections of fine particles by an electrostatic precipitator with DC or pulse energized prechargers," Journal of Aerosol Science, vol. 29, Supplement 2, no. 0, pp. S1127-S1128, 1998.

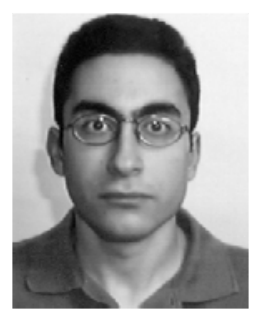

Athanasios C. Mermigkas (GSM'13) was born in Athens, Greece, in 1983. He received the MEng degree in Electrical and Computer Engineering from the University of Patras, Greece in 2009. His masters thesis for the above degree was in co-operation with the National Technical University of Athens (NTUA), Greece, regarding faults in distribution network lines. He then moved to Scotland where he received his MSc in Electrical Power Engineering with Business at the University of Strathclyde, Glasgow, UK in 2010, conducting research on Plasma closing switches for his MSc thesis.

In 2010-11 he worked as a research assistant in the high voltage technologies group at the same university, where he is currently pursuing his $\mathrm{PhD}$, working on a project to investigate the efficiency of micro electrostatic precipitation.

Mr Mermigkas is a member of the Technical Chamber of Greece (TEE), of the IET, and of the IEEE Nuclear and Plasma Sciences Society.

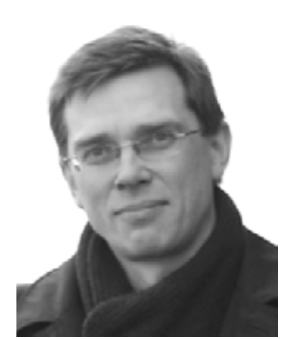

Igor V. Timoshkin (M'07) received the degree in physics from the Moscow State University (Russia) in
1992, and the Diploma and the Ph.D. degree from the Imperial College of Science, Technology and Medicine, (London, UK) in 2001. After graduation from MSU he worked as a Researcher at Moscow State Agro-Engineering University, and then at the Institute for High Temperatures of Russian Academy of Sciences before moving to ICSTM in 1997. He joined the Department of Electronic and Electrical Engineering of the University of Strathclyde (Glasgow, UK) in 2001 where he became a Senior Lecturer in 2011. His research interests include properties of solid and liquid dielectric materials, electronics of plasma discharges in condensed media, practical applications of electro-hydraulic and high-power ultrasound pulses, bio-dielectrics and effects of electromagnetic fields on biological objects.

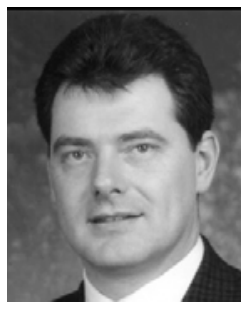

Scott J. MacGregor (M'95) received the B.Sc. and Ph.D. degrees from the University of Strathclyde, Glasgow, U.K., in 1982 and 1986, respectively. He is currently with the University of Strathclyde, where he became a Pulsed-Power Research Fellow in 1986, a Lecturer in pulsed-power technology in 1989, a Senior Lecturer in 1994, and a Reader and a Professor of high-voltage engineering in 1999 and 2001, respectively. He has been Dean of Engineering at the University of Strathclyde since January 2010. His research interests include high-voltage pulse generation, high-frequency diagnostics, high-power repetitive switching, high-speed switching, electronic methods for food pasteurization and sterilization, generation of high-power ultrasound (HPU), plasma channel drilling, pulsed-plasma cleaning of pipes, and stimulation of oil wells with HPU.

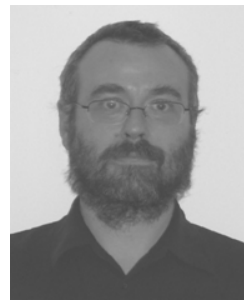

Martin J. Given (M'99-SM'11) is currently a Senior Lecturer in the Department of Electronic and Electrical Engineering at the University of Strathclyde. He received a degree in physics from the University of Sussex in 1981 and a PhD in electronic and electrical engineering from the University of Strathclyde in 1996. His research interests include, ageing processes and condition monitoring in solid and liquid insulation systems, high speed switching and pulse power applications.

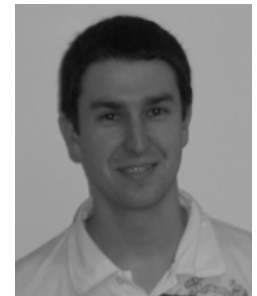

Mark P. Wilson (M'10) was born in Stranraer, Scotland, in 1982. He received the B.Eng. (with honours), M.Phil., and Ph.D. degrees in electronic and electrical engineering from the University of Strathclyde, Glasgow, U.K., in 2004, 2007, and 2011, respectively.

$\mathrm{He}$ is presently working as a Teaching Associate at the University of Strathclyde, where he continues to investigate surface flashover of solids immersed in insulating oil.

Mark is a member of the IEEE Nuclear and Plasma Sciences Society, from whom he received a Graduate Scholarship Award in 2011, the IEEE Dielectrics and Electrical Insulation Society, and the IET.

Tao Wang received the B.Eng and M.Sc degrees from Northeast China Dianli University (China) in 1993 and 1996 respectively, and the Ph.D. degree from

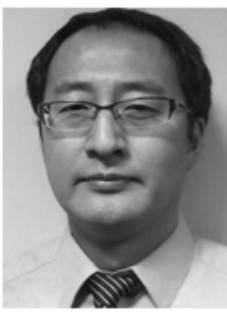
the University of Strathclyde (Glasgow, UK) in 2005. $\mathrm{He}$ then joined the Newland Entech as a research fellow developing high efficiency industrial ozone generator. He joined the department of Electronic and Electrical Engineering of University of the Strathclyde as a lecturer in 2010. His research interests include non-thermal gas discharges and their applications in gas synthesis, water disinfection and advanced oxidation process in water. 